\title{
NÁUFRAGOS Y BUFONES EN LAS CRÓNICAS URBANAS DE ALFONSO ALCALDE
}

\section{CASTAWAYS AND JESTERS IN ALFONSO ALCALDE'S URBAN CHRONICLES}

\author{
OLGA OSTRIA R.*
}

Resumen: El multifacético escritor chileno Alfonso Alcalde produjo una descomunal y heterogénea obra, gran parte de la cual ha quedado, por desgracia, en los márgenes de la memoria literaria nacional. El ejercicio del periodismo, que nutrió especialmente su narrativa, constituye un terreno aún más postergado. En el contexto de un proyecto de rescate y estudio de la escritura "referencial" de Alcalde, este artículo se aboca a interpretar una selección de aquellos textos, en su condición de "periodismo literario", y concretamente la configuración de los personajes que en ellos se lleva a cabo. Estos devienen, en definitiva, un genuino puente entre los diversos géneros de su compleja producción, lo que constituye una estrategia interdiscursiva que permite apreciar una fusión de los puntos de vista periodístico y artístico, propia de las crónicas urbanas contemporáneas.

Palabras clave: Alcalde, crónica urbana, literatura chilena, marginalidad, dialogismo.

Aвstract: The multifaceted Chilean writer Alfonso Alcalde produced a colossal and heterogenous body of work, most of which unfortunately has been relegated to the margins of the country's literary history. The profession of journalism, which especially contributed to Alcalde's narrative, is a field even more neglected. Within the context of a project dedicated to the recovery and study of Alcalde's "referential" writing, this article seeks to interpret a selection of those texts understood as "literary journalism", with a focus on the way in which they develop characters. These characters constitute a genuine bridge between the diverse genres within Alcalde's complex corpus, and can be read as an inter-discursive strategy that allows for the fusion of journalistic and artistic points of view found in the contemporary urban chronicle.

KEYwORDs: Alfonso Alcalde, urban chronicle, Chilean literature, marginalization, dialogism.

Recibido: 01.04.16. Aceptado: 13.06.16.

* Este artículo constituye parte de los resultados del proyecto de investigación "El periodismo literario de Alfonso Alcalde”, Universidad del Bío-Bío (DIUBB 130926 3/R), concluido en 2015.

** Doctora en Estudios Latinoamericanos. Universidad del Bío-Bío, Concepción, Chile. Correo electrónico: eostria@ubiobio.cl 


\section{INTRODUCCIÓN}

Signado desde siempre por la marginalidad, cual beatnik, Alfonso Al$\checkmark$ calde (Punta Arenas, Chile, 1921-1992) solía deambular en trenes de carga, comer y beber en bares y mesones de "mala muerte" y codearse con la más variada gama de personalidades. Desempeñó, en esos rumbos, múltiples y sorprendentes oficios: ayudante de panadero, maderero en minas bolivianas, traficante de caballos en el Matto Grosso, 'cuervo' de una funeraria, nochero de dudosos moteles, entre varios otros. Tal versatilidad se reproduce, asimismo, en su descomunal y heterogénea producción escritural (novelas, ensayos, cuentos, biografías, poemas, textos dramáticos, reportajes, crónicas, traducciones, guiones televisivos y radiofónicos), gran parte de la cual ha quedado, por desgracia, en las afueras de la memoria literaria nacional.

El ejercicio del periodismo alimentó particularmente la obra literaria de Alcalde, contribuyendo al cultivo de lo que se ha llamado un "realismo popular", manifestado principalmente en sus narraciones, y entendido este como una "inmersión profunda y genuina en la realidad del pueblo chileno" ("Memoria chilena") -tendencia que lo vincula a las escrituras de sus coetáneos José Miguel Varas, Nicolás Ferraro y Franklin Quevedo. Así también sus letras han sido asociadas a un "surrealismo popular" (Geisse, 2007, p. 22), por la inclusión de situaciones irreales, delirantes y/o excéntricas. El proyecto de Alcalde, que por su complejidad y amplitud no puede ser aquí examinado en detalle, constituye con todo un honesto "intento de atrapar experiencias populares" (Concha, 1973, p. 12), esa percepción del mundo desde la mirada de los más desposeídos que el escritor se afanó en investigar continuamente.

Es en esa línea que compone sus más destacados reportajes: Comidas y bebidas de Chile (1972) y Reportaje al Carbón (1973) -ambos parte de la colección Nosotros los chilenos-; Marilyn Monroe que estás en el cielo (1972), Vivir o morir (1973), Toda Violeta Parra (1979), Vivir sin Chile (serie de ocho fascículos acerca del exilio) ${ }^{1}$; y Gente de carne y hueso (1971), semblanzas biográficas. Existe, además, una inmensidad de material desperdigado en periódicos y revistas, y otro tanto, inédito, de modo tal que esta faceta del escritor tomecino ${ }^{2}$ constituye un terreno aun más desconocido para los lectores y la crítica.

\footnotetext{
${ }^{1}$ Esta referencia aparece en la bibliografía de la antología de Alcalde, Algo que decir (2001).

${ }^{2}$ Alcalde nace en Punta Arenas, pero se autoadopta en la Región del Biobío, particularmente en la zona costera de Tomé y Coliumo, donde decide acabar con su vida en 1992.
} 
Declarado admirador del denominado "nuevo periodismo", surgido en los años 60, Alcalde tendía a buscar en el oficio más libertades expresivas, pese a que parecía creer que el lenguaje periodístico se alejaba de su estilo literario y que, a fin de cuentas, lograba separar, no sin esfuerzo, ambas labores $^{3}$. En este sentido, distanciándose de otros cronistas latinoamericanos, no exhibe aquella "excepcionalmente lúcida conciencia de la crónica, desde el punto de vista de su relación con el tiempo de lo cotidiano moderno" (Morales, 2009, p. 59), que poseía, por ejemplo, el chileno Joaquín Edwards Bello, ni su estructura multiforme y cargada de posibilidades discursivas.

Con todo, sostenemos en este trabajo que la heterogeneidad de la producción de Alcalde ha sido concebida bajo un fuerte trazado intra e intertextual, lo que otorga a su proyecto la consideración de una obra total (Salas, 2008, p. 172). Sus textos exhiben, en verdad, rasgos transversales de creatividad, y los escritos que interpretamos en lo que sigue devienen, desde este postulado, un territorio intermedio donde se puede advertir la coexistencia de su visión de mundo como literato y como periodista. Ello convierte a Alcalde en un cronista de nuestros días y ratifica, a la vez, su propia mirada sobre su propuesta escritural: "el diálogo es el fundamento de mi obra" (Geisse, 2007, p. 15). En el marco de esa dinámica intertexual de las letras alcaldeanas, este artículo persigue, por consiguiente, leer una selección de sus textos referenciales ${ }^{4}$ en su condición de periodismo literario, esto es, desde un punto de vista que los concibe como conjunto de escritos heterogéneos, donde conviven formatos y enfoques periodísticos, con estilos, estrategias, y recursos provenientes de la ficción con visiones y configuraciones literarias.

\section{ALCALDE CRONISTA}

También conocida como "periodismo narrativo" o simplemente "crónica urbana", esta forma textual breve, nómade y fraccionada se resiste a una clasificación tradicional, fija y perdurable. Es justamente ese perfil indeterminado el que le ofrece la facultad de trasladarse entre mundos escriturales diversos y, así, conjugar la "realidad" y la imaginación.

\footnotetext{
${ }^{3}$ Así se señala en el artículo "Alfonso Alcalde promueve nueva experiencia editorial" (El Sur, 7 de febrero de 1985).

${ }^{4}$ Se trata de una selección realizada a partir de un extenso corpus -reportajes, crónicas, reseñasrecopilado en el diario El Sur (Concepción, Chile) y correspondiente a dos periodos de producción: $1968-1972$ y $1988-1992$.
} 
A los consabidos antecedentes de la crónica en América Latina, la crónica de conquista y de colonia, y la modernista decimonónica ${ }^{5}$, es interesante incorporar lo que George Steiner (1982), en el marco de su reflexión sobre la novela del siglo XX, entiende como una crisis de la ficcionalidad. Auspiciada por el surgimiento de unos medios de comunicación de masas que introducen en nuestra vida el mundo en imágenes, este fenómeno se caracteriza por una especie de "apetito de realidad" (Hauser, 1980, p. 302), y consecuentemente propugna el surgimiento y el triunfo de obras de carácter documental. Tal tendencia denominada por él "poética del documento o postficción” (Steiner, 1982, p. 104), consiste fundamentalmente en una amalgama de géneros que es capaz de configurar el carácter urbano y tecnológico de la cultura occidental: "En este género contemporáneo que podría llamarse 'alto periodismo', las técnicas heredadas de la novela juegan un papel decisivo. La mirada del periodista político y social es heredera directa de la mirada del novelista" (p. 105). De esta forma, las artimañas y argucias novelísticas son puestas al servicio del archivo. En los mejores resultados, se consigue aunar la amplitud de la perspectiva del periodismo y la profundidad de la mirada del novelista, mediante la aleación de información y de recursos literarios, como ocurre en la nonfiction novel (Weber, 1980, p. 74).

Configurándose, en suma, como un discurso fuera de lugar, este tipo de textos posee la libertad de incorporar biografía, testimonio, historia, periodismo y, por supuesto, literatura. Escritura plural, móvil, "bastarda" (en el decir de Pedro Lemebel ${ }^{6}$ ) yuxtapone, con irreverencia a veces, prácticamente toda forma de conocimiento del mundo, de expresividad discursiva, norma o registro: el habla popular y la imagen poética, la alta y baja cultura, lo canónico y lo marginal; desmarcándose así de todo molde fundamentalista. Coincidentemente, Alfonso Alcalde encarna esa actitud rupturista y anticanónica de la crónica actual cuando declara haber leído "de un tirón que es como comerse un pollo crudo- desde un tal Homero hasta el himno del Colo-Colo" (1970, p. 371), o bien, cuando en la propia "Nota preventiva al lector" que da inicio al poemario El panorama ante nosotros, confiesa que "intrusió desde Simónides hasta los himnos deportivos" (2007, p. 14).

Según se observa, en esta especie de montaje, la crónica contemporánea -y la de Alcalde, como veremos- tiende a rescatar lo cotidiano y corriente,

\footnotetext{
${ }^{5}$ Para profundizar en dichos antecedentes, véase, entre otras publicaciones: Rotker, (2005), Ramos, J. (2002), Chillón, A. (1999).

${ }^{6}$ Se trata de una expresión que Lemebel usa en muchos textos. Véase, por ejemplo, "Entrevista a Pedro Lemebel: Géneros bastardos" (2001).
} 
los relatos invisibles, por carecer de aparente significación frente a los dominantes, las historias menores, los "inútiles" datos curiosos y las perspectivas descartadas.

Dada su plasticidad, estas verdaderas "metáforas de la modernidad" (Morales, 2009, p. 68) gozan de la opción de concretarse en múltiples tendencias, entre las cuales se encuentra -según la estudiosa colombiana, Mariluz Vallejo (1997) ${ }^{7}$ - la "crónica-semblanza o de retrato", que "perfila un personaje vivo o muerto con un suculento anecdotario (muy común como nota necrológica o tarjeta de despedida)" (p. xviii), a la que nos abocamos específicamente en este artículo. Desde luego, son comunes en ellas las narraciones de situaciones cómicas o tragicómicas, como suele darse, por cierto, en la mayoría de los textos alcaldeanos.

\section{MAGOS, PAYASOS Y LÁGRIMAS}

De habla sencilla y directa, y ligada a una concepción estética de la cultura cómica popular (de sugerente tendencia rabelesiana), la escritura total de Alcalde se nutre del universo del circo, no solo como un espacio concreto, sino más bien en cuanto simbología de la existencia, como percepción y representación del mundo: visión tragicómica, contradictoria y, hasta cierto punto, carnavalizada, donde el jolgorio, la astucia y la magia subvierten la miseria imperativa. La risa y la desdicha en un mismo rostro. Por ello es que en numerosos cuentos del escritor transitan payasos, mujeres de goma y equilibristas, que junto a maestros "chasquillas", pescadores, y chispeantes y emotivos ebrios, se baten a diario con tormentosas circunstancias. $\mathrm{Mu}-$ chos de ellos son, en efecto, la encarnación ficcional de los seres de carne y hueso que habitan el periodismo literario de Alfonso Alcalde.

Marginados en muchos sentidos, los homicidas renombrados -y moralmente rebajados- $y$ sus asesinatos sin resolver resultan notable foco de atención en el autor tomecino, especialmente en la última década de su producción, quien tiende a enaltecerlos, mediante la lúdica narración de sus "hazañas". Así, el conocido Emile Dubois ${ }^{8}$, criminal francés que fue,

\footnotetext{
${ }^{7}$ Vallejo distingue, además, los siguientes tipos de crónica: crónica-glosa, crónica-relato, crónicadrama, crónica-folletín, crónica-crítica, crónica-parodia, crónica especializada, crónica autobiográfica, crónica-comprimido, crónica en verso, crónica-epístola y crónica-diccionario (Prólogo, p. xviii).

${ }^{8}$ Quien también inspira la notable novela de Carlos Droguett, Todas esas muertes (1971a). De paso, ambos escritores coinciden en su actitud admirativa de determinados crímenes y asesinos. Droguett (1971), además, escribió un elogioso y comprensivo ensayo sobre Alcalde: "La literatura chilena de espaldas a la realidad nacional" (1971b).
} 
después de varias persecuciones, atrapado y fusilado en Chile, es tratado con profunda admiración como un "artista", un "saltimbanqui de circo que siempre vivió alucinado por el misterio de la vida y la muerte" (Alcalde, 1989c, p. 4). De igual modo, Phan Van Loc, protagonista de un crimen pasional, es descrito como un romántico, "actorazo, bufón de comedia, que se dio el gusto de reírse de la policía" (p. 4), y que se disfrazaba como un mago, brillante, camaleónico. No obstante, maestro del engaño, el refinado oriental termina siendo un "mal asesino". Sentenciado a muerte, el ídolo cae humanizado ante la contemplación melancólica de un enunciador cuya sensibilidad poética se escapa, incluso a su pesar:

No estaba preparado para morir y tenía miedo. Aquella madrugada lloró a la espera de las primeras luces del alba. Sus piernas se negaban a sostenerlo. Algunos gendarmes fraternos lo ayudaron a sentarse en el banquillo. No fue tarea fácil porque también está comprobado que resulta más fácil matar que morir. Luego se escuchó la descarga y levantaron vuelo los pájaros que estaban columpiándose en las ramas de los árboles (p. 5).

Ennoblecida su existencia y poetizada su muerte, los protagonistas circenses del imaginario alcaldeano se verán con frecuencia estampados por la mirada maravillosa o surrealista del escritor, muy propia de su cuentísti$\mathrm{ca}$, donde abundan hechos extraordinarios, situaciones disparatadas y excentricidades, que dan cuenta de la fantasía y la desbordante imaginación de Alcalde. En ellos se descubren, por ejemplo, los profundos vínculos de amistad y solidaridad entre humanos y animales, dudosos "maestros" cuyas reparaciones dejan refrigeradores envueltos en llamas y cocinas congeladas, teléfonos que derraman agua y mangueras musicales ${ }^{9}$.

El pintor Julio Escámez deviene, desde este enfoque, un ente verdaderamente mágico en la pluma de Alcalde, para quien su "vida -constante peregrinación- [posee] el contorno de una aventura singular, un poco inexplicable, feérica y alucinante [, donde] lo inesperado es lo cierto y la fantasía parece ser la realidad" (1970d, p. 3). Así, el autor explica que el

\footnotetext{
${ }^{9}$ Véase El auriga Tristán Cardenilla y otros cuentos (1971) y Las aventuras de El Salustio y El Trúbico (1973). Alcalde procura no sólo desplazarse más allá de las fronteras de la realidad, sino también de los límites del cuento, como forma discursiva, al incluir allí diálogos, nóminas de personajes y lugares de acción; rasgos que acercan sus relatos a la dramaturgia. Como contrapartida, La consagración de la pobreza (1988), la emblemática pieza teatral del autor, es protagonizada por los clásicos personajes de su narrativa, el Salustio y el Trúbico. Ello constata la tendencia alcaldeana a transitar intergenéricamente por sus diversas creaciones.
} 
pintor "Champurrea con insignes maestros tanto en Japón como en China" y que "Fakires, marqueses, y altezas (...) lo reciben. En todos estos rincones aparece Escámez [-como en ensueño-] siempre incrédulo, un tanto ingenuo, bordeando innumerables peligros, como un aventurero de serial" (p. 3). Casi convertido en un Marco Polo contemporáneo, se nos cuenta finalmente que el artista se ha "marginado por completo de la pintura oficialista, pero irónicamente, su "universo, multicolor, apocalíptico [y hasta satánico por momentos], no limita con nada” (p. 3).

Ahí está, también, "Doña Leo y sus 140 maridos" (Alcalde, 1989a), quien por "la magia de las circunstancias, también pasaría a llamarse Leodecia, Lionor, Leontina, Leodina y Leovina" (p. 4). Oriunda de Lirquén, "la mujer baja, llamativa, bastante maquillada y con un anillo en cada dedo" (p. 4) sería elegida para transformarse en la protagonista de un programa de televisión en el que se le buscaría esposo. Desde el propio título del escrito, el enunciador flirtea con la tradición literaria latinoamericana, con lo fantástico surrealista, pero también con el drama telenovelesco, y nos relata sobre el diluvio de cartas y propuestas de matrimonio que comienza a recibir doña Leo, convertida en un verdadero suceso nacional. Registro de la soledad, el texto comparte una serie de párrafos seleccionados de esa avalancha de confesiones y promesas: "La imagen de su rostro quedó grabada en mí, en lo más profundo de mi corazón. Bastaría que me llamara para volar a su lado y quedarme para siempre" (p. 5). Aunque "Doña Leo sí tiene quien le escriba", al final de cuentas triunfa el desencuentro: el galán escogido por la cortejada no podrá esperarla eternamente, mientras "ella se mueve en medio de los aromas de las frutas del mar" (p. 5), atendiendo las mesas de su humilde restaurante costero. Abandonando, entonces, la condición de novia y estrella de televisión, doña Leo se volcará a su negocito de barrio, donde continuará esperando por el amor, pero ahora con una cajita de zapatos y las 140 cartas de sus enamorados.

Esta crónica nos permite reparar, además, en un rasgo interesantísimo en la obra narrativa de Alcalde que, desde luego, encuentra eco en sus crónicas: la acción (vinculada a la idea de carnaval en la cosmovisión bajtiniana) de la coronación y el destronamiento, desarrollada por muchos de los personajes del autor (Geisse, 2005). Tanto doña Leo, los homicidas importados, como los protagonistas de los cuentos "Almacencito La Gloria" y "El peregrino del Golfo", o los mismos El Salustio y El Trúbico, parecen alcanzar un momento de gloria, de superación de la miseria o el desamparo, que rápidamente da pie al descenso y al regreso de las antiguas circunstancias. En general, ningún relato de Alcalde descubre un cambio en los modos 
de vivir que definen a los personajes, quienes tienden a mantenerse en los ámbitos de la cultura popular, de la pobreza y la marginalidad, sin lograr, en definitiva, sus cometidos. Se trata, pues, de sujetos fallidos, desventurados y solitarios, pero después de todo festivos y esperanzados. En efecto, la amargura o el dolor no son unívocos en los textos de Alcalde, casi siempre van de la mano del chascarro, la fiesta y la burla.

La crónica "Alejandro Reyes: Un pintor ambulante" (Alcalde, 1989b) da cuenta magistralmente de ello: historia del tomecino Alejandro Reyes, de sus trágicos inicios y de sus variados oficios. El obrero, sastre, peluquero logrará después de grandes esfuerzos dedicarse a su verdadera vocación: la pintura. Vinculándose estrechamente a otros artistas como Elías Zaror ("un encuentro de dos talentos que llevan su secreto a cuestas", p. 7), Rafael Ampuero y Hugo Cárdenas, organizará el Círculo de Bellas Artes en Tomé. "Atriles y paletas en mano salen a recorrer los cerros: atardeceres gloriosos, vericuetos de las calles donde se escuchan hasta los pasos que nunca llegaron, niños dulcificados por la pobreza y la alegría de estar vivos" (p. 7). Los artistas, en radical idealismo, deciden regalar sus obras a la gente, que las reciben con dudoso cariño "iTanto color en tan poco espacio!" (p. 7). Todo es arte, nobleza y romanticismo hasta que Reyes advierte que los cuadros obsequiados sirven de "icomedero a las gallinas!", sus "árboles humanos que surgen como un himno" (p. 7) y esos rostros que hablan de amores y tristezas, quedan picoteados en medio de las risas de los pobladores. Mientras las gallinas dan muestras de felicidad, otro de los cuadros aparece vistiendo el espacio de un vidrio roto. Emerge entonces la imagen de circo, donde humor y padecimiento coexisten en una sola mueca. $Y$ también la reflexión sobre la futilidad del arte en la miseria, e incluso sobre cómo la cruda cultura popular se mofa de lo que se ha erigido en las alturas como "obra artística". Derrotado pero vivo, el show debe continuar y Reyes, sobrevivir, de modo que se decidirá por el oficio de fotógrafo, con lo cual luego se irá quedando solo, "a su modo"; dice Alcalde: "la vida vivida a la manera tomecina" (p. 7).

\section{Otros peregrinos}

Durante los tempranos setenta, Alfonso Alcalde dedicará buena parte de sus crónicas a grandes famosos de la época, nacionales y sobre todo extranjeras: grandes escritores, actores de Hollywood, músicos, personajes de la política internacional, astronautas, deportistas, etc. Sin embargo, resaltan aquí las versiones no oficiales de las historias de estas figuras que, ante los 
ojos del poeta, se hallan igualmente descolocadas, periféricas, dado su carácter extravagante y su condición de explotados por una industria inmoral. Con ellos saldrá a flote, entonces, la perspectiva crítica configurada en estos escritos, muy a la manera de la crónica urbana actual. Ciertamente, junto con la temática mediática, estos tipos de textos exhiben un frecuente carácter de denuncia y cuestionamiento del mundo, el cual se adapta de acuerdo a las relaciones que establecen con cada coyuntura, con las instituciones de la literatura, el periodismo y, por supuesto, con el mercado y los medios de comunicación.

Pero el interés de Alcalde por dar cuenta de lo ignorado, lo descartado y lo aún no canonizado, tiene que ver con una concepción en torno a lo político-social que ampara su escritura, y con un proyecto que lo vincula a la propuesta del mexicano Carlos Monsiváis, de poner "lo marginal en el centro" (2001, p. 11), esto es, visibilizar la cultura popular, los relatos menospreciados, las experiencias e interpretaciones omitidas o desechadas por los discursos hegemónicos.

Así lo demuestran, por lo demás, diversas crónicas-reportajes (la historia del submarino nazi que habría arribado a las costas de Coliumo o del cuasi asesinato de Fidel Castro en su visita a Tomé ${ }^{10}$ ), en las que Alcalde introduce el fragmento, el punto de vista opacado, empleando, desde luego, variados recursos ficcionales. Los lados B de las biografías exitosas serán, en suma, para el poeta tomecino, materia prima tanto para poblar su universo poético y narrativo, como para cuestionar el mundo capitalista de mediados del siglo XX.

La semblanza de Verushka (1970e, p. 3), top model de aquella década, es un ejemplo interesante de esta arista, al aparecer ella con todos los síntomas de los productos de la propaganda. Considerada una mujer "fuera de este mundo" (p. 3) por su descomunal altura, con "su cara de día lunes" (p. 3), la maniquí es ambigua e indiferente: "Bosteza oportunamente frente a la fortuna o el amor" (p. 3), pues, según narra con cierto desdén el autor, "su destino es dormir. Pero dormir con alevosía" (p. 3). Como dato curioso, Alcalde cuenta que el padre de Verushka estaba entre el grupo de prusianos que intentó asesinar a Hitler, por lo que fue fusilado. Junto a un familiar inicia, como consecuencia, un peregrinaje (otra vez) por varios países del Viejo Mundo. Hasta que un día le ponen uniforme y número y no conoce "sino el hambre y la infinita tristeza de los niños solos" (p. 3). Esas escenas

\footnotetext{
${ }^{10}$ Se trata de crónicas aparecidas en "La Gaceta" del diario El Sur el 9 de febrero 1992 y el 21 de octubre de 1990, respectivamente.
} 
de horror la continuarán desvelando, a pesar de la gloria reciente -se nos relata con una voz ahora cómplice.

Del sarcasmo, por momentos claramente machista ${ }^{11}$, a una irremediable empatía, el enunciador acaba personificando en "la interminable muchacha negra" (p. 3) a la sociedad actual y a su cultura pop que prospera durante estos años. De "terrible frialdad" (p. 3), es la mujer convertida en pura imagen: vacía, durmiendo-inerte, y entregada a un destino inexorable, a una humanidad mecanizada (las repercusiones de su biografía a Marilyn Monroe son aquí potentes (Alcalde, 1972)). Capturada por la cámara, ha convertido al registro fotográfico en la única manera de sobrevivir, pues, paradójicamente la foto y su "click mágico -declara la modelo, según Alcalde-constituyen un triunfo sobre la muerte, la desaparición y el cambio" (p. 3). Resuenan aquí las reflexiones de una contemporánea, Susan Sontag (2006), al respecto: "una vez terminado el acontecimiento, la fotografía aún existirá" (p. 26). Cabe reconocer que el universo de las imágenes confiere, en verdad, inmortalidad: ahí radica su poder misterioso y, a veces, siniestro. La falsa sonrisa, la sonrisa muerta, pero eterna, de Verushka deviene retrato fatídico de una cultura audiovisual deshumanizada.

Auténtico ventrílocuo, la presencia "imparcial" del enunciador se filtra entre las anécdotas de sus reseñados, al traducir sus recuerdos, sentimientos y "verdades". Constatando el carácter literario de estas crónicas-semblanzas, se desarrolla en ellas una imagen mucho más penetrante y reflexiva de los protagonistas y los acontecimientos que en el periodismo tradicional, la cual expresa, a su vez, aquella peculiar visión de mundo que caracteriza los textos de Alcalde. Ello explica que en muchos de los escritos de esta época también coexista, junto a la percepción trágica de la vida, el tono humorístico, caricaturesco, configurado frecuentemente a partir de un registro y un léxico popular criollo que se contrapone a la solemnidad, al status o al glamour típico de las celebridades mundiales de entonces. Tal es el caso de la semblanza a Serge Gainsbourg (1970b, p. 9), el mítico compositor francés (que cantaba con Brigitte Bardot), aquel nada apuesto galán de la música popular sesentera, cuyas creaciones "llevaban la tragedia adentro" (p. 9), toda vez que había experimentado con sus padres "un largo peregrinaje por todos los matices de la miseria" (p. 9). "Envuelto en el humo del cigarrillo y la marihuana -dice el escritor-, creyó no tener destino" (p. 9). A pesar de todo, la voluntad humana prevalece: "A los 15 descubrió que

\footnotetext{
${ }^{11}$ La compara, por ejemplo, con "una escultura un tanto abstracta: plana por fuera y hueca por dentro" (p. 3).
} 
sería pintor incomprendido (..,) lo malo es que los críticos le encontraron toda la razón -comenta el cronista, con malicia-. ¡Jamás vendió un cuadro! Desparramaba pintura sobre la tela con la misma gracia que un buey intenta un vals en la cuerda floja" (p. 9). Un día confirmó que tenía las orejas más descomunales de Francia (...) y, "pastelero a tus pasteles", se dedicó a la música que, finalmente, lo haría triunfar. "Su rostro tan poco agraciado sigue motivando el estudio de varios sociólogos” (p. 9) -insiste el escritor. A la postre, Gainsbourg puso fin a sus presentaciones en vivo "cuando en un music-hall tuvo que salir después de un mono que hacía algunas gracias jugando con un globo" (p. 9).

La risa burlona, propia de la cosmovisión carnavalesca, como la entiende Bajtín (1990), que emana como consecuencia del infortunio o de hechos indignos, se ve retocada, modificada, con el recurso de lo patético, concebido aquí como una determinada mezcla de elementos cómicos y trágicos, concretamente asociada a lo ridículo y a aquello que produce vergüenza ajena o pena, y que permite revelar los extremos de la existencia humana ${ }^{12}$. En ese tenor, lo patético se conforma con frecuencia desde la crueldad o el humor negro animado por una deformidad física o algún accidente. Se trata, en consecuencia, efectivamente de una risa ambivalente, pero no solo alegre y sarcástica (como distinguiría el mismo teórico ruso, para las fiestas de la plaza popular en la Edad Media y el Renacimiento), sino además, profundamente melancólica, lastimosa y, gran parte de las veces, conmovedora. En este sentido, tampoco hay en Alcalde una condena moral al personaje despojado, ridiculizado, como ocurriría en el carnaval. Lo gracioso no implica dicha sanción moral en sus textos, es más bien un gesto que suscita la reflexión y termina dando paso a una especie de piedad por la víctima, más allá de la caricatura. La risa triste, la máscara cómica y la trágica en la obra de Alcalde expresan, con todo, una posición en el mundo: un sentir en conflicto, en paradoja continua.

Recapitulando, los personajes de las crónicas alcaldeanas estudiadas se constituyen en sujetos que bordean lo freak (noción que, muy a propósito, suele ligarse a lo circense), antihéroes, a veces pobres, otras exitosos financieramente, pero siempre solitarios y dueños de un sufrimiento casi cróni-

\footnotetext{
${ }^{12}$ Según la Real Academia de la Lengua, el término "patético" se refiere a aquello "capaz de mover y agitar el ánimo infundiéndole afectos vehementes, y con particularidad dolor, tristeza o melancolía" (Diccionario Real Academia de la Lengua [en línea]).

No obstante, el concepto posee un uso mucho más habitual, a partir del siglo XX, vinculado a lo grotesco o a lo ridículo, que parece más coherente con la intención y los efectos configurados por los escritos aquí analizados.
} 
co a cuestas. Entre "derrumbes, alegrías, deseos de vivir y de morir, bailar en la cuerda floja y tensa de la existencia" (Alcalde, 1970e, p. 3), figuran, por tanto, el sinsentido de la vida y la desolación (temas que acosan a Alcalde con mayor nitidez en su poesía). Tal como el folclorista chileno Críspulo Gándara (1970e, p. 9), quien anciano ya, "con los ojos apagados y la mirada triste" recuerda sus éxitos de antaño cuando era el animador obligado. "Nadie se acuerda de uno...", dice el payador que, a fin de cuentas prefiere perderse en sus memorias, donde nadie "le gana". Pobre y olvidado, coronado y destronado, se encuentra hoy ad portas de la muerte o tal vez medio muerto ya: "Agonizando con un pie vivo, descansando con un pie muerto (...) muerto a medias en sociedad (...) todo mezclado: por un lado, la muerte y por el otro, también" (Alcalde, 2007, p. 55). Con similares sentimientos, refiere el escritor a la autora de Una muerte muy dulce (1964), Simone de Beauvoir (1970c), cuyo lánguido semblante se construye en el texto a partir del oxímoron sostenido: "La amarga Simone. Todavía conserva en el rostro esa dulzura tolerante y triste" (p. 3). Es ella el "naufragio total: ha perdido la fe" (p. 3). "Todo lo que quería hacer -habla la intelectual en la voz de Alcalde- escribir libros, saber cosas, lo he hecho, pero he fracasado. Tuve lo que quise. Pero finalmente lo que quería era siempre otra cosa" (p. 3).

En relación con la sociedad de consumo y la cultura occidental, representada en estas crónicas a partir de los elementos urbanos (la publicidad, la moda, lo pop, el mercado), los personajes tienden igualmente a desarrollarse en términos contradictorios. Esto es, nunca plenamente insertos en dicho mundo o, mejor, aparentemente dentro, pero, en esencia, instalados en los márgenes: fatales outsiders.

\section{UN DIÁLOGO DESESPERADO}

A la actualidad y la veracidad de los hechos expuestos en los escritos examinados se incorpora, sin duda, la pretensión estilística y una gran variedad de estrategias literarias. Asimismo, cohabitan en ellos el habla popular y claros elementos poéticos que brotan, aun sin explícita voluntad; condiciones que ciertamente permiten visibilizar su carácter de crónicas urbanas. El bello e imprescindible texto bautizado "Shuto" (Alcalde, 1989d), correspondiente a los postreros años de producción del autor, acaba por ilustrar dicha fisonomía de las crónicas alcaldeanas. En él, el enunciador parece rendirse irremediablemente a esa forma de concebir y representar el mundo a través de un tono poético, colmado de melancolía, y, por momentos, 
existencialista. La narración versará, esta vez, sobre un dibujante de caricaturas, de seudónimo Shuto, quien "desde su primer llanto siempre estuvo en contra de todo" (p. 2), y cuya madre pintora lo mece en sus primeros días en "azul, en ocres y verdes tormentosos" (p. 2). Luego de relatarnos el breve periplo del protagonista entre la guerrilla y el estudio de leyes, la crónica se centra en lo que será su auténtica profesión, "chistoso", y entablará un diálogo cada vez más íntimo con las creaciones del dibujante. En ellas se expresa, por ejemplo, la crisis del amor actual por medio de la ausencia del "Cupido bueno" (p. 3). Los dibujos muestran, entonces, a los robustos angelitos asaltando a las parejas en la oscuridad con sus arcos y flechas. $\mathrm{O}$ bien, critican el uso deshumanizado de la tecnología y los medios de comunicación con profunda agudeza. Pero Alcalde se enfocará especialmente en una de las "series de monos" (p. 3) bautizada como "Los náufragos". Para él, se trata de la "figura del solitario intransigente porque desea que vengan a rescatarlo sin mucho entusiasmo" (p. 3). (...) "El hombre es la soledad multiplicada -ahonda-, y dentro, alrededor y también por fuera lo rodea el contratiempo de la sobrevivencia. En la desdicha de continuar residiendo en nuestra tierra" (p. 3). De la soledad al silencio, un paso, en la interpretación alcaldeana de las ingeniosas ilustraciones y la vida del artista: "Shuto descubre que la palabra es la causante de todos los males de la historia. Por eso sus monos, que se publican en Noruega, Finlandia, Holanda, Italia, no dicen ni pío" (p. 3). Para las líneas finales quedará la revelación de la identidad del biografiado, la principal ironía del texto: "Shuto, Juan Sebastián Alcalde, nacido a las orillas del susurrante Biobío, su cómplice. Entre mudos se entienden cada vez que se ven. El silencio tiene la palabra, hijo" (p. 3). La elipsis previa es impecable, pues la develación desconcierta y enternece. El remate, y su potente carga de emotividad, obliga, naturalmente, a otra lectura: la del diálogo desolado -único posible al parecer- del padre escritor con las creaciones calladas de su hijo esquivo, la develación de una distancia y un apego inmensos por igual, del abandono y la complicidad. Transformada en otra crónica, surgen en ella múltiples espacios vacíos, silencios cargados de sentido, silencios que resuenan en el texto. De nuevo la ambivalencia plena.

Los personajes de los textos periodístico-literarios de Alfonso Alcalde, estos magos y payasos a la deriva, no constituyen solo sustento o inspiración para sus escritos propiamente literarios, sino un genuino puente entre los diversos géneros de su escritura toda, los cuales, a fin de cuentas, no poseen aduanas definidas. Atravesando todos los formatos y registros, dichos personajes devienen estrategias de interdiscursividad, que permiten 
apreciar una fusión de los puntos de vista periodístico y artístico. En fraterno dialogismo con el resto de la obra del escritor chileno, las crónicas revelan además una sensibilidad poética que tampoco discrimina moldes genéricos y se escapa como un instinto irrefrenable. Aquel "sonido literario" -que Monsiváis (1980, p. 39) gustaba atribuir a las crónicas contemporáneas-, a veces susurro, otras, melodía honesta, impregna efectivamente la escritura referencial de Alcalde, la que acaba reflejando múltiples facetas de su mundo poético. Y no únicamente por el tratamiento de los mismos temas que persiguen al autor (la soledad, la pobreza, la marginalidad, la muerte) ni tampoco por la serie de recursos ficcionales o retóricos a los que esta escritura acude (el relato de suspenso, el guiño fantástico y la sensibilidad maravillosa o surrealista), sino, más aún, por la configuración de esa cosmovisión de mundo incongruente, conflictiva, que caracteriza su producción total y se evidencia en la constante presencia de disparidades esenciales: lo alto y lo bajo, lo local y lo cosmopolita, lo poético y lo popular, lo mágico y lo realista, la risa y el llanto, el patetismo y la burla festiva, la desolación y la esperanza, la vida y la muerte: "Soy el incongruente, el que no calza en su espejo (...) y desde afuera lo ataca y desde adentro lo niega" (Alcalde, 1998, p. 96).

Alcalde cultiva, en definitiva, una escritura desgarrada, que -como explicaría Roland Barthes (2006) - no es sino representación de una realidad fracturada: "porque la sociedad no está reconciliada, el lenguaje necesario y necesariamente dirigido, instituye para el escritor una condición desgarrada" (p. 85). Sin embargo -y la paradoja continúa aflorando-, prevalece en esta palabra quebrada una búsqueda de diálogo. Efectivamente, la forma de la crónica constituye una apertura, una capacidad para cruzar fronteras, no solo discursivas, e incluir al otro, de manera que también hace posible vincular un proyecto estético con un imaginario político. La crónica de Alfonso Alcalde reelabora a personajes famosos desde perspectivas no exploradas, relata historias no oficiales, le añade a la literatura chilena voces excluidas y situaciones no registradas ni imaginadas, que acaban manifestando un poderoso sentido dialógico, y convirtiendo estos escritos en una forma de reconocimiento de la otredad y, por tanto, en un anhelo de constitución de comunidad ${ }^{13}$.

Los protagonistas de las crónicas-semblanza aquí examinadas, seres extraordinarios, asombrosos, con increíbles vidas pero completamente solos,

\footnotetext{
${ }^{13}$ La idea se condice plenamente con la lectura de El Panorama ante nosotros propuesta por Magda Sepúlveda (2010): "Alcalde elabora un sujeto plural (...) e inventa la región del Bío Bío [sic] como una comunidad de sentido" (p. 106).
} 
completamente muriendo, y muriendo, al mismo tiempo, por el encuentro y la compañía, se constituyen aquí en la encarnación más patente de aquella ambivalencia escritural que define la producción alcaldeana. Desde este horizonte, francos alter egos de Alcalde, a través de ellos, el autor queda configurado en sus propias letras como otro bufón triste que, por un lado, no quiere ser rescatado, sino vivir y morir a su modo, a la manera tomecina, en radical margen y en soledad intransigente $y$, por otro, se halla inexorablemente $-\mathrm{y}$ por fortuna- condenado a la palabra.

\section{REFERENCIAS}

Alcalde, A. (1970a). Impresiones. Antología de la poesía chilena contemporánea (pp. 366-379). Santiago: Editorial Universitaria. (1970b). Serge Gainsbourg. "La Gaceta" de El Sur, 14 de jun., p. 9. (1970c, junio 21). Simone de Beauvoir. Una mujer en crisis permanente.

"El Sur dominical" de El Sur, p. 3. (1970d, octubre 25). Julio Escámez. "El Sur dominical" de El Sur, p. 3. (1970e). Críspulo Gándara. El Sur, 15 de nov., p. 9. (1970f, diciembre 3). Verushka. "El Sur dominical" de El Sur, p. 3. (1972). Marilyn Monroe que estás en el cielo. Santiago: Ediciones Universitarias de Valparaíso. (1989a). Doña Leo y sus 140 maridos, "La Gaceta" de El Sur, 22 ene., pp. 4-5. (1989b, febrero 12). Alejandro Reyes: Un pintor ambulante, "La Gaceta" de El Sur, pp. 6-7. (1989c, marzo 12). Homicidas importados, "La Gaceta" de El Sur, pp. 5-6. (1989d). Shuto, "La Gaceta" de El Sur, 16 abr., pp. 2-3. (1998). Autorretrato № 1. Naín Nómez (ed.). Siempre escrito en el agua (pp. 96-97). Santiago: Lom. (2001). Algo que decir. Santiago: Editorial Cuarto Propio. (2007). El panorama ante nosotros. Santiago: Altazor.

Bajtín, M. (1990). La cultura popular en la Edad Media y en el Renacimiento. El contexto de Francois Rabelais. Madrid: Alianza Editorial S.A.

Barthes, R. (2006). El grado cero de la escritura. México: Siglo XXI.

Concha, J. (1973). Historias de risas y lágrimas. José Miguel Varas, Alfonso Alcalde, Nicolás Ferraro, Franklin Quevedo. Santiago de Chile: Editorial Quimantú.

Chillón, A. (1999). Literatura y periodismo. Una tradición de relaciones promiscuas. Barcelona: Universidad Autónoma de Barcelona.

Droguett, C. (1971a). Todas esas muertes. Madrid: Alfaguara.

Droguett, C. (1971b). La literatura chilena de espaldas a la realidad nacional. Mensaje, 202/203, 477-484. 
Entrevista a Pedro Lemebel. Géneros bastardos, en Marcelo Mellado (ed.) (2001). Textos profanos, 1, Santiago de Chile: Cuarto Propio.

Geisse, C. (2005). Presencia de la cultura popular y la carnavalización literaria en los cuentos de Alfonso Alcalde. Tesis de Magíster, Pontificia Universidad Católica de Valparaíso.

(2007). Introducción. La consagración de la pobreza. El absurdo tesoro de la miseria. En: Alfonso Alcalde, La consagración de la pobreza (17-24). Santiago: Altazor.

El Sur (1985, febrero 7). "Alfonso Alcalde promueve nueva experiencia editorial", p. 6.

Hauser, A. (1980). Historia social de la literatura y del arte. Barcelona: Guadarrama.

Memoria Chilena. Alfonso Alcalde. Presentación [en línea]. Disponible en: http://www.memoriachilena.cl/temas/index.asp?id_ut=alfonsoalcalde (1921-1992)

Monsiváis, C. (1980). A ustedes les consta. Antología de la crónica en México. México: Era. Era.

(2001). Entrada Libre. Crónicas de la sociedad que se organiza. México:

(2009). Joaquín Edwards Bello: crónica y crítica de la vida cotidiana chilena. Revista Chilena de Literatura 74, 57-78.

Ramos, J. (2002). Desencuentros de la modernidad, Santiago: Editorial Cuarto Propio.

Rotker, S. (2005). La invención de la crónica. México: Fondo de Cultura Económica.

Salas, F. (2008). Alfonso Alcalde. Discursos/prácticas 2, 171-178.

Sepúlveda, M. (2010). Concepción recobrado en la poesía chilena. Taller de Letras 47, 105-115.

Sontag, S. (2006). Sobre la fotografía. México: Alfaguara.

Steiner, G. (1982). El género pitagórico, Lenguaje y silencio (pp. 99-112). Barcelona: Gedisa.

Vallejo, M. (1997). La Crónica en Colombia: Medio Siglo de Oro. Bogotá: Presidencia de la República.

Weber, R. (1980). The Literature of Fact: Literary Nonfiction in American Writing. Ohio: Ohio University Press. 